\title{
Gestación, historia redaccional y recepción de Espacio de Juan Ramón Jiménez
}

\section{Gestation, Compositional History and Reception of Espacio by Juan Ramón Jiménez}

\author{
Juan José Rastrollo Torres \\ Universidad Pompeu Fabra \\ jjrastrol@gmail.com \\ ORCID iD: https://orcid.org/0000-0003-4204-2308
}

\section{RESUMEN}

Espacio de Juan Ramón Jiménez, «uno de los monumentos de la conciencia poética moderna» según Octavio Paz, es un largo poema unitario en tres fragmentos con una historia redaccional espaciada, provisional y compleja. La composición se fue gestando, con una misma «pulsión» (la conciencia de inmensidad espacio-temporal y eternidad), a partir de fragmentos de poemas que el poeta fue publicando en diversas revistas y diarios a lo largo de más de diez años. En este artículo, además de revisarse el proceso de composición (paralelo al poema en prosa Tiempo), la historia editorial, la recepción y la bibliografía de Espacio, se lo adscribe a la tradición del «poema extenso moderno» y a su método compositivo.

Palabras Clave: Espacio; Juan Ramón Jiménez; composición; recepción; Tiempo.

\begin{abstract}
Espacio by Juan Ramón Jiménez, «one of the monuments of the modern poetic consciousness» according to Octavio Paz, is a long and a unitary poem in three fragments with a spaced and complex editorial history. It was gestating over more than ten years from short poems that the poet had been published independently in several magazines and newspapers. In this article, it is exposed the editorial and bibliographic history of Espacio and it is ascribed to the tradition of the modern long poem and its compositional method.
\end{abstract}

Key words: Espacio; Juan Ramón Jiménez; Composition; Reception; Tiempo. 


\section{Estado De LA CUESTIÓN: SU GeSTACióN}

Desde el punto de vista formal, Espacio de Juan Ramón Jiménez puede considerarse un poema extenso ${ }^{1}$ en prosa unitario, estructurado en tres fragmentos y, desde el del contenido — como De rerum natura de Lucrecio, Bajo forma humana de Mario Luzi o Blanco en el blanco de Eugénio de Andradese muestra como un poema cosmogónico, «metafísico» ${ }^{2}$, meditativo y autobiográfico («canta y cuenta» ${ }^{3}$ su vida). El texto se ajusta, por tanto, a la definición que del moderno género poético da Octavio Paz o la investigadora Margaret Dickie en On the Modernist Long Poem, al definir esta nueva tipología en términos de extensión-duración y explicar este tipo de composiciones en función de la importancia que desempeña el tiempo en su gestación y desarrollo: «But the poems themselves have a history, a long period of gestation and development, in which they were revised and reconsidered and changed in structure and focus» (Dickie 1986: 4).

La estudiosa americana, rastreando la historia redaccional de largos poemas canónicos como La tierra baldia, El puente, Paterson o The Cantos, demostró que la gestación de estos textos abarcaba periodos de más de diez años y, en la mayoría de los casos, el autor había ido publicando fragmentos de los mismos en revistas de poesía de su tiempo. Es paradigmático, por ejemplo, el caso de William Carlos Williams, quien - como Juan Ramónañadió a Paterson un quinto libro a modo de epílogo diez años después de que saliera a la luz como poema completo en cuatro libros, constituyendo en realidad un work in progress, un compendio de gestación dilatada mediante composiciones publicadas independientemente. En este sentido, Espacio

${ }^{1}$ Sobre la naturaleza, caracterización y clasificación del poema extenso moderno, consúltense mis dos artículos sobre la cuestión: «Hacia una caracterización del poema extenso moderno» en el no 4, 2011 de la Revista Forma y «La genericidad del poema extenso moderno: hacia una clasificación de sus modos de expresión» publicado en el n ${ }^{\circ}$ 7, 2016 de Castilla. Estudios de Literatura. En estos se define esta modalidad genérica como un discurso poético de cierta extensión, fragmentario, multigenérico, híbrido - aunque de esencia lírica, lo descriptivo, lo narrativo, lo dialógico y lo lírico se congregan-, musical, polifónico, autobiográfico y germinado desde la pulsión inicial de una memoria que inicia un viaje errático del pasado al presente a fin de realizar un balance de vida. Como podemos comprobar, todos estos aspectos - junto a la complejidad de su ideario, lo dilatado en el tiempo de gestación y el hecho de que estamos ante un poema-libro- nos permiten adscribir el texto de Juan Ramón a la categoría de «moderno poema extenso».

${ }^{2}$ En conversación con Ricardo Gullón, tratando la naturaleza de su libro Diario, Juan Ramón definía su idea de «lo metafísico» coincidente con la esencia de Espacio: «Es un libro metafísico: en el que se tratan los problemas de la creación poética, los problemas del encuentro con las grandes fuerzas naturales: el mar, el cielo, el sol, el agua...» (Gullón 2008: 73).

3 Según la definición y método de composición que Octavio Paz refiere sobre el poema extenso en su artículo «Contar y cantar (Sobre el poema extenso)». 
(1942-1942/1954) es un poema paradigmático de esta tipología, ya que se gesta a lo largo de trece largos años y cumple dichos criterios. La tesis de Dickie exponía además que la mayoría de poemas extensos habrían surgido a partir de una idea primigenia, de un breve poema que debió de alcanzar tal complejidad psicológica en el autor que generó en él una incontenible pulsión por dar continuidad a la intención inicial. En el caso del poema largo meditativo de Jiménez, el verdadero motivo temático, punto de partida (y de llegada, respectivamente) y eje vertebrador de su programa poético es la búsqueda de una conciencia interior individual (yo histórico), integrada en un estado de conciencia universal (yo total) $)^{4}$, en el cual los límites entre espacio y tiempo, asimilados por la interioridad, se difuminan confluyendo en un punto cenital que da pleno sentido al tránsito de la vida a la muerte. Este tema clave en torno al que gravita su escritura última ya se hallaba trabado en la esencia de la mayoría de los poemas de su libro anterior al exilio, donde el autor expresaba que el yo poético se integra en una «estación total» que supone la experiencia de la vida eterna a través de la vivencia del eterno retorno y de que el mundo adquiere forma en su conciencia ( Y lo soy todo», confiesa en «El otoñado»). En La estación total ya late la poética de Espacio y el inicio de una tercera etapa — «verdadera» o «suficiente»-, marcada por la contravención de las demarcaciones de tiempo y espacio, y por la introspección en su propia conciencia como un dios. De hecho, algunos de los poemas de La estación total, como apuntó y seleccionó la estudiosa Almudena del Olmo Iturriarte, establecían un sistema de relaciones que posteriormente se hallarán presentes en Espacio. Por ejemplo, textos como «Desde dentro», «La otra forma», «Samoén», «Espacio» ${ }^{5} \mathrm{y}$, especialmente, «El otoñado» (1935) expresaban ya una consubstanciación con la naturaleza a través de cierto misticismo («entre dioses descielados») desvinculado de cualquier forma de fe. En «Desde dentro», describe un proceso místico inverso, desde la infinitud de la realidad externa (luz, iris, palmera...) hacia el «adentro», o conciencia interior que el poeta identifica con la sola poesía: «Desde entonces ¡qué paz! / no tiendo ya hacia fuera / mis manos. Lo infinito / está dentro. [...] Ella, Poesía, Amor, el centro / indudable.» (Jiménez 2005a: 911) ${ }^{6}$. En «La otra forma», el poeta bosqueja un viraje de su creación hacia otra forma

\footnotetext{
${ }^{4}$ Según la denominación de Javier Blasco Pascual en la «Introducción» de Juan Ramón Jiménez. Antología poética.

${ }^{5}$ No confundir con el poema extenso Espacio, motivo de nuestro estudio, para el que emplearemos la letra cursiva.

${ }^{6}$ En nuestro estudio, citaremos la poesía y prosa de Jiménez a partir de las ediciones de Javier Blasco y Teresa Gómez Trueba de la BLU de Espasa-Calpe: Obra poética. Vol. 1. Obra en verso (2005a) y Obra poética. Vol. 2. Obra en prosa (2005b). Por la reconstrucción ecdótica que los distintos editores llevan a cabo, esta debe considerarse en estos momentos la edición canónica de la obra juanramoniana.
} 
que encarne la entrega y la disolución del yo a través de la naturaleza; devuelto así a una conciencia universal, a una especie de hierogamia que le guíe hacia la unión con un absoluto no desgajado del cuerpo ni de la vida terrena: "Ya no sirve esta voz ni esta mirada. / No nos basta esta forma. Hay que salir / y ser en otro ser el otro ser. / Perpetuar nuestra esplosión gozosa» (Jiménez 2005a: 914). En «Samoén», desde la conciencia de un perpetuo retorno («eterno azul»), el yo poético anuncia un ascesis hacia la quinta estación a través de «escaladas granas» (Jiménez 2005a: 916). En «La plenitud», describe el estado de gracia que le aguarda tras la vida como una vivencia (en este mundo) de y en una naturaleza pura donde las sombras de lo sagrado también resplandezcan: «(Y el agua una se ve más. / El color es más él, más sólo él, / el olor solo tiene un ámbito mayor, / el calor todo se oye más.)» (Jiménez 2005a: 918). El poema «Espacio» ${ }^{7}$ prefija la muerte como un estado formal transitorio desde una conciencia individual («tu forma») a otra universal: «Mas tu conciencia queda difundida, igual, mayor, / inmensa, / en la totalidad» (Jiménez 2005a: 926). Finalmente, es «El otoñado» el poema donde Juan Ramón — como un Narciso - expresa con mayor júbilo la epifánica experiencia de conciliación y fusión del espacio propio y limitado del poeta con el universo externo: «Estoy completo de naturaleza, / en plena tarde de áurea madurez, / alto viento en lo aún verde traspasado. [...] Y lo soy todo. / Lo todo que es el colmo de la nada, / el todo que se basta y que es servido / de lo que todavía es ambición» (Jiménez 2005a: 914). Como vemos, el poeta es ya un dios, porque como un demiurgo conjuga en su interioridad («lo grande elemental en mí») la esencia infinita de lo externo («la tierra, el fuego, el agua, el aire»), nombra sin contención, incorpora su conciencia limitada a la corriente infinita de la conciencia universal, ilumina lo sombrío del espacio exterior («doro el lugar oscuro») y asume en su yo interior la totalidad externa («Y lo soy todo»). «El otoñado» es, sin lugar a dudas y a pesar de su fecha composición ${ }^{8}$, el texto fundacional de la etapa «suficiente» de Juan Ramón y la base en la ontogénesis ${ }^{9}$ de Espacio, donde

${ }^{7}$ No confundir con el poema extenso Espacio, motivo de nuestro estudio, para el que emplearemos la letra cursiva.

8 «El otoñado» se publicó por primera vez en uno de los llamados Cuadernos de Juan Ramón Jiménez. En concreto, en Hojas (1935).

${ }^{9}$ En nuestro análisis y acerca de la importancia de los materiales prototextuales de Espacio, aplicaremos el enfoque de la genética textual o «crítica genética», disciplina que estudia la posibilidad de sistematizar, organizar y profundizar metodológicamente en el tratamiento del conjunto heteróclito de elementos que están situados alrededor del texto (la llamada «tercera dimensión textual»). En este sentido, el texto es sólo la parte de un conjunto superior que abarcaría los elementos paratextuales y pretextuales, es decir, todo cuanto precede al texto y da fuente de su creación (el «antetexto»); pero no en el sentido de G. Genette en Palimpsestos, para el que el «antetexto» se refiere a las citas que preceden al cuerpo central de una obra, sino los apuntes hallados en el archivo de un autor, los tanteos 
— como si de una continuación de «El otoñado» se tratase- declara tajante desde el inicio: «Los dioses no tuvieron más sustancia que la que tengo yo» (Jiménez 2005b: 1269) ${ }^{10}$. Hay, además, una total continuidad entre Espacio y el último libro que Juan Ramón escribió en España, y una misma digamos «pulsión», en el sentido de que el yo del poeta es otro, según palabras del autor, con «una necesidad de conciencia interior»: un yo que quiere eternizarse y se reconoce fuera de sí, formando parte de la naturaleza integrada en su interior. Así lo considera también Almudena del Olmo Iturriarte en «Una propuesta de lectura» a La estación total:

Necesidad de conciencia interior y ambiente en lo limitado de nuestra morada de hombre». En estos términos cifra Juan Ramón lo que supone su tercer tiempo poético a la altura de 1949. Una ajustada aseveración contenida en la «Nota» que cierra Animal de fondo, pero que no sólo determina este poemario central de su última época, sino también La estación total y Espacio, como punto de partida y punto de llegada respectivamente (Olmo Iturriarte 2009: 125).

O en su introducción a Espacio, para Obra poética (2005) de la BLU de Espasa:

Creo que puede afirmarse que todo el discurso artístico del Jiménez de la última época, que a mi modo de ver inaugura La estación total y clausura el tercer fragmento de Espacio, gira en torno a un mismo eje: dar forma a través de la palabra a la exigencia central del yo poético juanramoniano, cifrada en la necesidad de lograr un estado de conciencia universal que le permita al poeta explicar con coherencia su vida y su muerte y, al mismo tiempo, otorgar un sentido pleno al universo de su poesía y a su actividad creadora (Olmo Iturriarte 2005: 1255-1256).

En las Canciones de la nueva luz, un total de sesenta y tres textos compuestos entre 1923 y 1936 - aunque revisado, ampliado, concluso y publicado definitivamente en 1946 por la editorial Losada de Buenos Aires_-, el poeta también formula su canto en torno a cómo su conciencia interior interioriza lo otro haciéndolo renacer en él. Destacamos el poema «jY alerta!», donde irrumpe, como en el final del tercer fragmento de Espacio («Conciencia... Conciencia, yo, el tercero, el caído, te digo a ti: ¿me oyes, conciencia?», Jiménez 2005b:

sobre sus poemas, las noticias manuscritas que ha ido dejando y, en definitiva, los papeles desordenados de diversa entidad que repercuten en el proceso de la creación textual. En conclusión: su gestación. Sin ánimo de caer en el error de cierta crítica poética actual que confunde «texto» con «antetexto», diríamos que la crítica genética acaba allá donde la crítica textual empieza. Sobre la crítica genética, consúltense los Essais de critique génétique (1979) de Louis Hay o el libro La Genetique des textes (2000) de Pierre Marc de Biasi.

${ }_{10}$ En nuestro artículo citaremos los poemas Espacio y Tiempo a partir de la mencionada edición de Almudena del Olmo Iturriarte: Obra poética. Vol. 2. Obra en prosa (2005b), coordinada por Javier Blasco y Teresa Gómez Trueba. 
1284), con un diálogo o un monólogo con su conciencia: «Tesoro de mi conciencia / ¿dónde estás, cómo encontrarte?» (Jiménez 2005a: 962). En Canciones también se halla el poema «Hueco», donde la conciencia interior no halla presencia en el mundo exterior y se esfuerza por adaptarse al silencio y a la oquedad; o «Mensajera de la estación total» y «Luz tú» (en la tercera sección), cuyo desenlace queda representado también por el vacío — como en el episodio del héroe hueco del tercer fragmento de Espacio - y la constatación de otra forma de conciencia interior. Sin embargo, en esta última sección la conciencia fracasada renace en otras representaciones externas (el pájaro, la luz, el chopo, la rosa, la fuente, la mujer o la estrella), que el poeta concibe como formas perceptibles de eternidad. Estos seres constituirán el universo de Espacio, representando la plenitud de lo otro como única esperanza de la conciencia ante la presencia de la ultimidad y su vacío. Además, este estadio silente de no-lugar y no-tiempo representa el universo en el que hemos de ubicar el yo poético de Espacio: un mundo de afortunados seres ajenos al poeta como el «mirlo» o el «gorrión», que traen su canto renovado cada primavera, y en los que también cada primavera el poeta quiere encarnarse, dado que representan la imagen viviente del «eterno retorno» («el retorno gustoso de la vida», nos dice en «En flor $50 »$, que remite a la experiencia de renovación que su quincuagésimo estadio le ofrece).

Se puede apreciar también otro diálogo intertextual - perceptible en el despliegue conceptual de símbolos isotópicos recurrentes e intertextualesentre «El otoñado», la prosa «El chopo solitario» ${ }^{11} \mathrm{y}$ las siguientes líneas del primer fragmento de Espacio, donde el poeta evoca la Colina de los Chopos de la Residencia de Estudiantes: «Hermoso es no tener lo que se tiene, nada de lo que es fin para nosotros, es fin, pues que se vuelve contra nosotros, y el verdadero fin nunca se nos vuelve. Aquel chopo de luz me lo decía en Madrid, contra el aire turquesa del otoño: Termínate en ti mismo como yo» (Jiménez 2005b: 1270). Destaquemos la importancia de cómo en los tres textos referidos se congrega el tiempo en el espacio. Advirtamos además que — más que el espacio físico- Juan Ramón define la propia conciencia y sus movimientos internos de flujo y reflujo como la búsqueda de una fusión del ser individual con la conciencia universal a través de la escritura. Con respecto a su libro posterior, En el otro costado, y retomando la tesis de Margaret Dickie, ¿quién podría negar que poemas como «Los pájaros de yo sé dónde», «Árboles hom-

${ }^{11}$ Reproducimos aquí un fragmento de «El chopo solitario»: «Yo lo veía ya en mis hondos sueños de adolescente, doblado, como un indómito arco de fuego, por el viento grande del vehemente crepúsculo de otoño - de esos ocasos cortos, ácidos, únicos, casi falsos, que levantan hasta su sorda negación al cénit-; como un prodijioso meteoro de la tarde — súbito mártir secreto, arraigado sólo a su misterio errante-, derramando inútilmente en el potro de la alta soledad sus chispas bellas, gotas de roja luz, divinas hojas de oro» (Jiménez 1970: 89). 
bres», «En la mitad de lo negro», «Dios visitante», «Volcán errante», «Del fondo de la vida» o «Con ella y el cardenal» no estuvieron en la base fundacional o formaron parte de Espacio y, posteriormente, fueron descartados?

Como hemos ido avanzando, Espacio es un poema extenso en tres fragmentos con una historia redaccional y editorial ${ }^{12}$ espaciada y compleja. Los dos primeros fragmentos corresponden a los años 1941 y 1942 y se compusieron en Florida cuando el poeta tenía unos 60 años; la génesis del tercero representa una gran incógnita ya que, aunque quizá fuera gestado al mismo tiempo y en el mismo lugar que los otros dos, fue concluido y editado en 1954 - como demuestra el tono de la composición-, cuando Juan Ramón ya vivía en Puerto Rico. Este desorden cronológico y temático propicia al poema mayor interés si cabe. Pero, como sostiene Alfonso Alegre en su artículo "Génesis, contexto y versión final de "Espacio": algunas consideraciones», el origen de Espacio no es producto de ningún «milagro», ni un hecho aislado del resto de la obra del autor. No sólo es inseparable del libro en que el poema está incluido, En el otro costado; sino también del inmediatamente posterior a éste, el titulado Una colina meridiana; y también de La estación total:

Por los proyectos de Juan Ramón sobre «Espacio», así como por sus notas manuscritas en muchos de los originales de esta época, sabemos que un número importante de poemas en «En el otro costado»y de «Una colina meridiana» formaron parte en algún momento de «Espacio» (Alegre 2007: 23).

Las dos fechas (1941-1942), que adoptamos como punto de partida para la composición de este interminable monólogo, jalonan momentos importantes de su trayectoria poética y nos desvelan algunos aspectos que nos pueden ayudar a interpretar la historia redaccional del poema. Pero, ¿cuáles eran las pulsiones o las condiciones de vida, geográficas o físicas, en las que fue compuesto? Hemos hablado sobre cómo los primeros años de exilio de Juan Ramón en Puerto Rico y Cuba representaron un impedimento para el desarrollo de la labor poética; sin embargo, fue su definitiva instalación a partir de 1939 en Coral Gables —ese «trozo americano de Andalucía»— el momento decisivo que provocó en el poeta un sentimiento de reconciliación con el mundo, el

12 Avanzamos en estas líneas la historia editorial de Espacio, dejando para el siguiente apartado los datos más relevantes. El primer fragmento se publicó en verso libre por primera vez en Cuadernos Americanos, II (1943), núm. 5, pp. 191-205; el segundo, en la misma revista III (1944), núm. 5, pp. 181-183. El primer fragmento apareció, copiado de Cuadernos, en Las cien mejores poesías españolas del destierro, seleccionado por Francisco Giner de los Ríos, México, Signo, 1945, pp. 4-19. En 1954 se dio a la luz el tercer fragmento junto a los dos primeros en prosa en la revista Poesía Española, núm. 28, abril de 1954. Tras esta, se editaron de nuevo los tres fragmentos en prosa en la mencionada Tercera antolojía poética (1898-1953), Madrid, Biblioteca Nueva, 1957, pp. 851-880; y en la referida edición en la anterior nota: Pájinas escojidas (Prosa), selección de Ricardo Gullón, pp. 17-37. 
redescubrimiento del paisaje y la firme consideración de que no existen más fronteras que las de la propia conciencia humana. Y, finalmente, ¿qué cristalizó la redacción del poema? Está claro que el sentimiento de soledad y extranjería provocados por el exilio están en el germen de la escritura de aquellos años; pero, sin lugar a dudas, «la embriaguez rapsódica» que genera la pulsión creativa del poema y su forma extensa derivan sobre todo de la contemplación extasiada de la planicie ilimitada de las marismas de La Florida, que aúnan mar y tierra. En una entrada de Zenobia a su Diario el 10 de noviembre de 1939, comentaba que Juan Ramón estaba otra vez lleno de inspiración y añadía: «Las casas blancas, techos de teja y pinos le recuerdan a Moguer y su nostalgia fluye en verso. Es una suerte que vea a Moguer a distancia» (Camprubí 1996: 146). Mercedes Julià ${ }^{13}$ da relevancia a otra entrada de Zenobia el día 3 de abril de 1940, donde describe el momento epifánico que para Juan Ramón representó observar la inmensidad de las marismas de La Florida en una excursión en 1940, un año antes de escribir Tiempo y Espacio, en la que los Jiménez visitaron los Everglades (terreno pantanoso con una extensión de 6.000 interminables kilómetros cuadrados):

No le dije a J.R. hasta última hora que íbamos a cruzar los Everglades en su punto más amplio, y de nuevo, las descripciones que nos habían hecho, nos tenían nerviosos, así es que salimos a las 7.00 a.m. y nos encontramos atravesando, no el desierto que nos habían dicho, sino una extensa área pantanosa con unos pinos finos como con plumas y tal cantidad de vida silvestre que daba gusto. Las graciosas garzas de cuello largo salieron volando del agua en bandadas, asustadas por el ruido del automóvil. Había también unas horribles y grandes auras, que son como buitres, cebándose en cualquier cosa muerta que les hubieran dejado los que viajan de noche. Pasamos al lado de los restos de por lo menos 4 pequeños animales de mucho pelaje, J.R. insistía en que eran zorras... (Camprubí 1996: 201).

«A raíz de esta visita», nos dice Julià, «las marismas de la Florida se convierten para Juan Ramón en símbolo-marco o escenario ideal donde la unión de los dos ámbitos en que se resumían sus vivencias era posible: el de su niñez en Huelva, lugar de marismas, y el de su madurez en América» (Julià 2001: 63). Añadamos a la tesis de Julià que, en ese marco paisajístico, también evidenció Juan Ramón la idea de que no hay límites entre espacio y tiempo, porque era en ese «aquí» y ese «ahora» de la visita a los Everglades donde estaba descubriendo una orografía y cronología íntimas que ponían en conexión el paisaje de Moguer y de España; o las vivencias pasadas en su país con el entorno y la vida a la que se había visto abocado a vivir. La estudiosa coteja además la misma anécdota de la excursión a las marismas floridanas descrita de diversas formas en Tiempo y Espacio. Señalemos una cierta «región de intersección» entre ambos poemas, comprobando cómo el poeta moguereño

${ }^{13}$ En su artículo «Ámbitos americanos en el simbolismo del último Juan Ramón Jiménez». 
detalla en Tiempo con un estilo telegráfico cada animal observado o la experiencia mística («ausencia vertical completa», la llamaba él) de presenciar la naturaleza en estado puro, pero interiorizada en él:

El zorro destripado en la noche por un auto cegador, el conejo muerto en medio del camino, con la boca y los ojos más que vivos. Las auras negras volando en el aire aún de agua, cerca, por ellos, conejo y zorro. [...] Las grullas blancas que se levantan volando elásticas, blandas como flores. La serpiente que pasa en ondas rápidas, y la matamos con la rueda. La pareja de lentas tortugas, la mariposa ocre muerta como una flor, contra el cristal. El cangrejo que corre con la boca abierta. [...] Todo parece que me desconoce. Qué estraño me siento caminando vestido por este camino de las marismas inmensas. Y yo lo reconozco todo. A nadie, a nada le intereso y a mí me interesa todo. Veo toda la naturaleza como algo mío y ella me mira toda como algo ajeno... (Jiménez 2005b: 1335-1336).

En el poema Espacio, se hace referencia a esta misma visita a los Everglades, pero ahora las marismas simbolizan la unidad dentro de la diversidad y lo real-descriptivo da paso a lo visionario: «lo que me interesa es libertar sensación e inquietud» (Jiménez 1992: 236), dijo en una carta a Luis Cernuda. Observemos cómo el poema Espacio — descartando lo anecdótico o narrativointensifica el aspecto emotivo de lo observado y la unidad cósmica:

Las copas de veneno, ¡qué tentadoras son!, y son de flores, yerbas y hojas. Estamos rodeados de veneno que nos arrulla como el viento, arpas de luna y sol en ramas tiernas, colgaduras ondeantes, venenosas, y pájaros en ellas, como estrellas de cuchillo; veneno todo, y el veneno nos deja a veces no matar [...] Entramos por los robles melenudos; rumoreaban su vejez cascada, oscuros, rotos, huecos, monstruosos, con colgados de telarañas fúnebres; el viento les mecía las melenas, en medrosos, estraños ondeajes... (Jiménez 2005b: 1271).

Como hemos ido registrando, la larga gestación de todo poema extenso presupone un periodo dilatado de planificación y redacción, cuestión que nos alienta a rastrear también por los papeles íntimos del autor (diarios, cartas, memorias, entrevistas, aforismos...), cotejándolos con el texto definitivo. Los especialistas en Juan Ramón están de acuerdo en que el primer testimonio implícito de la escritura de Espacio se halla en una carta remitida a Pablo Bilbao Arístegui el 2 de febrero de 1941 desde Coral Gables, en la que aporta dos referencias presentes en el poema: los conciertos que él y Zenobia escuchaban por la radio los domingos por la tarde dirigidos por Bruno Walter en el Carnegie Hall de Nueva York, o la evocación del mítico director de orquesta Toscanini describiendo un viaje que ambos hicieron a Nueva York para verle dirigir un concierto de Brahms. También es especialmente significativa para la interpretación de Espacio una declaración dada en la carta remitida a Pablo Bilbao Arístegui: «Los domingos vamos al mar, de color indescriptible, a las marismas llenas de pájaros espléndidos. Como esto es todo llano, el cielo da una medida hermosa de su infinitud» 
(Jiménez 1992: 196). Es evidente que en su imaginario poético ya germinaba la idea de un poema que expresara esa idea de inmensidad espacio-temporal. En la misma carta también formulaba: «Trabajo, además, en dos libros nuevos, uno de verso y otro de prosa» (Jiménez 1992: 195). Juan Ramón se refiere, sin lugar a dudas, a los poemas Espacio y Tiempo, textos que según estos testimonios estaban siendo redactados simultáneamente. Señalemos que, aunque Juan Ramón los concibiera inicialmente como libros independientes, dado el paralelismo de temas y de escritura, a nuestro criterio formaban realmente parte de un proyecto único. Así lo considera Blasco Pascual:

Los dos textos, como conjunto, surgen del replanteamiento del yo, como historia - en esa «escritura del tiempo, fusión memorial de ideología y anécdota, sin orden cronológico», que es Tiempo- y como espacio de conciencia —en ese «poema de espacio» que es Espacio- (Blasco Pascual 1987: 92).

O se lo cuestiona la misma Olmo Iturriarte: «¿No será que Tiempo, un texto que en principio surge como paralelo y complementario de Espacio, acaba convirtiéndose en una suerte de borrador, muy peculiar y atípico, de una creación asimilada o subsumida más tarde por la evolución que sigue Espacio?» (Olmo Iturriarte 2005: 1264).

Siguiendo con la historia editorial del texto, Espacio se publicaría finalmente como una sección de En el otro costado, libro que, como otros, quedó inédito y sufrió múltiples revisiones. Sin embargo, las referencias explícitas a ambos poemas aparecerían más tarde, en 1943, a través de las confesiones hechas por el autor en dos cartas. Una iba dirigida a Luis Cernuda desde Washington en julio de 1943. En ella nos aportaba el dato revelador de que la historia redaccional del poema se inició en 1940:

Ahora, hace tres años, tengo en mi lápiz un poema que llamo «Espacio» y sobrellamo «Estrofa», y llevo ya de él unas 115 pájinas seguidas. Pero, sin asunto, en sucesión natural. Creo que en la escritura poética, como en la pintura o la música, el asunto es retórica, «lo que queda», la poesía. Mi ilusión ha sido siempre ser más cada vez el poeta de «lo que queda», hasta llegar un día a no escribir (Jiménez 1992: 237).

La otra, dirigida desde Washington al crítico Enrique Díez-Canedo el 6 de agosto de 1943, nos transmite una idea clara de cómo la dimensión espacio-temporal de ambas composiciones surge de la imagen de inmensidad $^{14}$

${ }^{14}$ Reproducimos aquí parte de la carta: «En la Florida empecé a escribir otra vez en verso. Antes, por Puerto Rico y Cuba, había escrito casi esclusivamente crítica y conferencias $[\ldots]$ La Florida es, como usted sabe, un arrecife absolutamente llano y, por lo tanto, su espacio atmosférico es y se siente inmensamente inmenso. Pues, en 1941, saliendo yo, casi nuevo, resucitado casi, del hospital de la universidad de Miami (adonde me llevó un médico de éstos de aquí, para quienes el enfermo es un número y lo consideran por vísceras 
suscitada por La Florida. Esta pulsión generada por la contemplación de la inmensidad fue recurrente a lo largo de los más de diez años en que el poema se fue gestando y revisando. Tal es así que en una conversación con Ricardo Gullón el 4 de marzo de 1954, cuando revisaba el tercer fragmento y lo estaba preparando para su definitiva publicación, todavía tenía muy presente la analogía entre las marismas floridanas, la orografía de su Huelva natal y Espacio. De esta manera se lo recordaba al crítico:

¿Conoce usted Miami? - me pregunta Juan Ramón- Es un arrecife de coral que se representa como una línea horizontal, recta. Pues bien, esa línea y ese paisaje me hicieron concebir según es el poema "Espacio", en cuya revisión estoy hoy trabajando. El poema quiere ser también algo de horizontes ilimitados, sin obstáculos; dar la impresión de que podría seguir sin fin, continuamente. A propósito de este poema, Gerardo Diego dijo que cada verso echa fuera al anterior. Y yo lo compararía también con un friso. Miami es como el poema: llano, amplio, sin una colina ni un obstáculo que se oponga a la vista: todo es espacio abierto, libre (Gullón 2008: 120-121).

Por otra parte, resulta extraño que en la carta remitida a Cernuda ya no mencione (como sucedía en la de Pablo Bilbao, a tan sólo un mes vista) la redacción paralela de Espacio («Estrofa») y Tiempo («Párrafo»). Y, por otra parte, ¿a qué 115 páginas se refiere Juan Ramón en su carta a Cernuda, si los dos fragmentos del poema no abarcan ni siquiera unas cincuenta? Quizá hablara de páginas manuscritas, pero estas declaraciones nos hacen considerar la posibilidad de que ambos poemas podrían haber sido realmente concebidos como un solo proyecto y de que Tiempo, texto autobiográfico en prosa («fusión memorial de ideolojía y anécdota»), que Juan Ramón abandonó y nunca tuvo intención de publicar, podría tratarse en realidad de un «borrador paralelo», que daría cuenta del asunto, la reflexión desordenada y la retórica compositiva del verdadero texto definitivo en verso libre: Espacio. No olvidemos que en el breve prólogo que encabeza Tiempo nos da una idea clara de que Espacio es una forma de escritura poética elevada que refleja la instantaneidad vertical; y Tiempo, por el contrario, simple prosa o «memorial» que transcurre en horizontal, como suceden los días y las horas. Reproducimos aquí el mencionado «prologuillo»:

La Florida, toda espacio, buena de volar, que me dio el alto poema en verso $E s$ trofa, me ha dado, tierra llana (baja) buena de andar, Párrafo, un memorial largo

aisladas), una embriaguez rapsódica, una fuga incontenible empezó a dictarme un poema de espacio, en una sola interminable estrofa de verso libre mayor. $\mathrm{Y}$ al lado de este poema y paralelo a él, como me ocurre siempre, vino a mi lápiz un interminable párrafo en prosa, dictado en prosa, dictado por la estensión lisa de la Florida, y que es una escritura de tiempo, fusión memorial de ideolojía y anécdota, sin orden cronolójico; como una tira sin fin desliada hacia atrás en mi vida. Estos libros se titulan, el primero, Espacio; el segundo, Tiempo, y se subtitulan Estrofa y Párrafo» (Jiménez 1992: 243). 
de prosa. Dos profundidades, otra vertical al cenit y al nadir, y una, esta, horizontal, a los cuatro sinfines (Jiménez 2005b: 1325).

Tiempo es, como afirmaba su biógrafa Graciela Palau de Nemes, «un manuscrito inédito no listo para publicación» que, por razones que desconocemos, desatendió apenas iniciado y sobre el que no volvió nunca más. Al respecto, escriben Llansó y Bejarano ${ }^{15}$ : «Su inacabamiento es absoluto, como si en algún momento Juan Ramón se hubiera olvidado de él y lo hubiera abandonado definitivamente» (Jiménez, 2012: 43). De hecho, en Tiempo no hay esquema argumental desarrollado de una manera lógica ni, mucho menos, cronológica. Con un aparente desorden y en un presente actualizado nos encontramos reflexiones sobre su escritura; opiniones críticas sobre otros autores («Fragmento $5 »)$; recuerdos de momentos vitales determinantes; observaciones sobre la vida política española vista desde el exilio («Fragmento 3»); evocaciones sentimentales de su Andalucía («Fragmento 6»), etc. Ese «lo que queda» esencial pudo ser realmente Espacio, el resultado poético de la sensación instantánea posterior a lo anecdótico de Tiempo, que no era más que «anécdota» y «composición», como rezaba en su carta a Cernuda. Leyendo entre líneas del «Prólogo» a Espacio, se puede comprobar cómo surge de la pluma de Juan Ramón una clara apoyatura a nuestra tesis de considerar Tiempo como literatura «adjunta» a Espacio: "Creo que un poeta no debe carpintear para "componer" más estenso un poema, sino salvar, librar las mejores estrofas y quemar el resto, o dejar éste como literatura adjunta» (Jiménez 2005b: 1286). Nicanor Vélez ${ }^{16}$ también hace referencia a las relaciones externas de Espacio con el resto de su obra y, de manera especial, con Tiempo. Con estas palabras explica el poeta y editor colombiano el verdadero sentido del término «carpintear» del que habla el prólogo a Espacio:

Carpintear aquí no quiere decir trabajar, pulir, labrar, corregir o construir el poema. Pues como bien sabemos, no sólo trabajó «Espacio» internamente (corrigiendo, quitando, añadiendo, puliendo, sacando o relacionando partes para hacerlas, finalmente, poemas independientes), sino que además le buscó sus relaciones externas con el resto de su obra: intentó hermanarlo con su poema Tiempo, lo hizo parte de su libro En el otro costado y lo insertó en una unidad mayor: Lírica de una Atlánti$d a$. Por tanto, creo que carpintear hay que entenderlo en otro sentido. Tal vez lo que le molestaba realmente a Jiménez era que alguien para hacer más largo un poema jugara al añadido, al collage y renunciara por completo a la poda (Vélez 2006: 215).

Por «carpintear» - estamos totalmente de acuerdo con Vélez- Juan Ramón entiende el método de composición de un poema largo como si en realidad

${ }^{15}$ Nos referimos a introducción de la siguiente edición: Jiménez, Juan Ramón (2012). Espacio y Tiempo, J. Llansó Martín y R. Bejarano Álvarez (eds.). Ourense: Linteo Poesía.

${ }_{16}$ En su artículo «Espacio o el movimiento del tercer mar de Juan Ramón Jiménez». 
fuese una suite de fragmentos inconexos e imbricados artificialmente. Construir un poema por adición, pulir o corregirlo no es «carpintear»; sino ceñirlo y ajustarlo a la expresión esencial del ritmo interior y la conciencia del poeta. En otras líneas del prólogo, el mismo Jiménez esboza su idea acerca de Espacio como un «poema de lo que queda» tras desechar de él lo argumental. Sirvan estas palabras de apoyatura a nuestra tesis: «Pero toda mi vida he acariciado la idea de un poema seguido (¿cuántos milímetros, metros, kilómetros?) sin asunto concreto, sostenido sólo por la sorpresa, el ritmo, el hallazgo, la luz, la ilusión sucesivas, es decir, por sus elementos intrínsecos, por su esencia» (Jiménez, 2005b: 1286). Tratemos ahora otro aspecto discutido de la historia de la gestación del poema juanramoniano. Joaquín Llansó y Rocío Bejarano en su estudio introductorio a Espacio y Tiempo insisten también en la idea de rebatir la extendida opinión que considera Espacio como «testamento poético» ${ }^{17}$ de Juan Ramón. La crítica — declaran ambos estudiosos - parte del error de considerar que el polémico tercer fragmento fue compuesto en la fecha de su revisión y posterior publicación (1953-1954) y no entre 1940 y 1945, fechas en las que ellos piensan que se compuso todo el poema (incluso el tercer fragmento) de manera unitaria. "No cabe», declaran, «querer ver en ellos algo así como distintos estados de ánimo, distintos cantos en cada uno de los fragmentos que los componen, y sin embargo así han querido verlo algunos» (Jiménez 2012: 35). La interpretación proviene también de la opinión del crítico Antonio Sánchez Barbudo ${ }^{18}$, quien planteó por primera vez la cuestión de la fecha de composición del tercer fragmento del poema: «No sé de cuándo será el primer borrador de este fragmento último. A veces, por lo que dice, parece estar escribiendo en Florida, y otras sólo recordando Florida. Probablemente este fragmento tercero fue empezado en Florida y corregido y terminado más tarde en Puerto Rico» (Sánchez Barbudo 1962: 216). Dos años después, en su introducción a la edición de Animal de fondo, Sánchez Barbudo consideraba además que el tercer fragmento reflejaba el bajo estado de ánimo en que encontraba Juan Ramón tras su viaje de vuelta de Uruguay y Argentina. En definitiva, defendía que había sido redactado en Puerto Rico, en los últimos años de creación del poeta (1953-1954) y constituía, por tanto, su «testamento poético». Como ya ocurría con la interminable corrección de sus poemas breves, fueron muchas las revisiones que Espacio sufrió desde su gestación en 1941 hasta la

17 La referencia de Llansó y Bejarano a la opinión generalizada del poema extenso de Juan Ramón como culminación de la obra juanramoniana procede de las consideraciones de Díaz de Castro en su artículo «Espacio como culminación de la poética de Juan Ramón Jiménez», donde coincide con otros críticos en que Espacio ha de estudiarse integrado en el conjunto de su obra, «culminándola como el resultado final de la introspección de Juan Ramón en su ideología poética y de la reflexión sobre las fronteras de la creación artística» (Díaz de Castro 1991: 268).

18 En La segunda época de Juan Ramón Jiménez (1962). 
fijación ecdótica y su definitiva publicación — prosificado, corregido por el propio Juan Ramón y en tres fragmentos - en la revista Poesía Española en 1954, bajo el título y subtítulo de Espacio (3 Estrofas). Su primera edición, Espacio (una estrofa) ${ }^{19}$, se corresponde con el actual «Fragmento primero» de los tres y se publicó en 1943 en México en la revista Cuadernos Americanos. Esta edición primera ya venía acompañada por el «Prólogo». En 1944 se publicaba en la misma revista el segundo fragmento con título «Espacio (fragmento primero de la segunda estrofa). Cantada $»^{20}$. Ambas publicaciones en verso libre aparecerán conjuntamente en una edición de $1945^{21}$ a cargo de Francisco Giner de los Ríos para la editorial Signo de México.

Sin embargo, existe una versión mecanografiada anterior a las de Cuadernos Americanos archivada en la Sala Zenobia y Juan Ramón Jiménez de la biblioteca del Recinto Universitario de Río Piedras. Tal vez sea la primera hecha a partir del original manuscrito, donde Juan Ramón iba tachando las palabras que dictaba a Zenobia y después reproducía en la copia manuscrita. Se considera la primera, aunque no se conoce su fecha exacta, porque en ella aparecen algunos versos que fueron marcados con un paréntesis en tinta roja y desechados de la versión definitiva de Cuadernos Americanos. Algunos de estos fragmentos rechazados se editaron de manera independiente a posteriori y otros - publicados con anterioridad en revistas de la época- se añadieron al poema. Ejemplos de ello son los siguientes poemas localizados por Arturo del Villa y Olmo Iturriarte: «Cantada», con título inicial «Al grito de las cimas», ubicado definitivamente en el fragmento tercero; "Como nosotros» (con otros títulos, «Para mi paso por debajo de ellas» y «Marismas verdes, azules»); «No están gozando», insertado al fragmento tercero a excepción de ocho versos; y, por último, el caso más conocido es el del poema en prosa «Leyenda de un héroe hueco» (diálogo final con su propia conciencia), publicado en La Nación de Buenos Aires el 11 de enero de 1953 (compuesto inicialmente en verso en 1947-48 con título «Un héroe hueco») e incorporado después con pequeñas variaciones como síntesis de Espacio. En definitiva, el hecho de que Espacio

19 En Cuadernos Americanos, México, Año II, Vol. XI, núm. 5, septiembre-octubre, 1943, pp. 191-205. A pesar de que la completa edición de 2005 a cargo de Almudena del Olmo Iturriarte para la BLU de Espasa-Calpe recoge en su "Apéndice» las variantes de las diferentes versiones de Espacio, aquí nos hemos remitido a su reproducción facsimilar en el «Apéndice 2» (Jiménez 2012: 313-332) de la edición de Llansó y Bejarano; del mismo modo - a fin de consultar las múltiples correcciones manuscritas del poeta sobre el texto ya editado-, hemos revisado los originales corregidos del prólogo y la copia apenas corregida posteriormente del fragmento primero de la misma edición de Cuadernos Americanos, que se vuelve a reproducir en el «Apéndice 3» (Jiménez 2012: 333-354).

${ }^{20}$ En Cuadernos Americanos, México, Año III, Vol. XVII, núm. 5, septiembre-octubre, 1944, pp. 181-183. También se halla en «Apéndice 2» de la edición de Llansó y Bejarano, aunque en este caso sin correcciones.

${ }^{21}$ En Las cien mejores poesías del destierro (1945). 
se esté componiendo y revisando durante años pone en entredicho la tesis de Joaquín Llansó, que considera que toda la composición se gestó entre 1941 y 1945, correspondiendo así a un solo momento redaccional y un único estado de ánimo. En este sentido, estamos absolutamente de acuerdo con Alfonso Alegre Heitzmann ${ }^{22}$ al decir que Espacio es «un poema de poemas», un conjunto de fragmentos resultado de la poda del poema texto inicial (115 páginas seguidas, como le dijo a Luis Cernuda). A partir de ese texto borrador, Juan Ramón fue quitando partes hasta dejar el poema en su versión definitiva, o haciendo de estas partes poemas independientes posteriormente incluidos en los distintos libros en que estaba trabajando en los años de la década de los 40 . Alegre también defendía que el tercer fragmento tuvo una historia redaccional paralela a la de los dos primeros fragmentos o, al menos, que ya estaba escrito antes de su prosificación en 1954. Su tesis se basa en los poemas que iban a formar parte de Espacio y después fueron incluidos en libros que datan entre 1943 y 1944, como Hacia otra desnudez y Lírica de una Atlántica. El especialista considera que cabe una reformulación de la cuestión a partir de las notas y los originales de los poemas escritos en la década de los años cuarenta:

En mi opinión, la falta de un estudio profundo del proceso textual de "Espacio", a partir de los distintos borradores, proyectos y notas del poeta, que se guardan en la Sala Zenobia y JRJ de la Universidad de Puerto Rico y que permanecen en parte inéditos, hacen que esas interpretaciones del sentido de Espacio, así como del lugar y significación de éste en la obra última de Jiménez, se sustenten sobre las bases muy poco sólidas (Alegre 2007: 23).

Sin embargo, la publicación de «Un héroe hueco» en 1953 nos hace pensar que quizá Juan Ramón tuviera más bien un proyecto inicial de su «Fragmento tercero» en el mismo momento redaccional de los dos primeros fragmentos; pero fue entre 1948 y 1953 cuando debió realizarse la redacción definitiva (si es que esto se puede decir de algún texto suyo). Sea como fuere, la idea tan juanramoniana de entender la creación literaria como una constante revivificación (en el sentido de un hacer y rehacer) y un obrarse sin límites que clausure ese proceso nos hace al menos tener la certeza de que el poema Espacio fue la espera de sí mismo a lo largo de sus más de diez años de gestación. De ello da cuenta el mismo Juan Ramón quien, a raíz de unas declaraciones que Guillermo de Torre realizó formulando que «el cangrejo» simbolizaba a la crítica, respondió en una carta a este el 20 de enero de 1953 rechazando dicha interpretación y demostrando que el poema Espacio es una composición que, a pesar de las consideraciones de su prólogo, se ha ido gestando con un hilo común a partir de poemas que el autor había ido publicando como breves

${ }^{22}$ En su mencionado artículo: «Génesis, contexto y versión final de "Espacio": algunas consideraciones». 
composiciones independientes en diversas revistas y diarios: «No sé qué es eso que dice usted de un crítico. Forma parte del poema más largo Espacio, cuyos fragmentos he venido publicando hace años en diversas revistas» (Jiménez 1992: 205). Lo cierto es que se puede decir que, hasta principios de 1954 - fecha de la revisión final en Puerto Rico y de la publicación definitiva-, Juan Ramón estuvo trabajando y prosificando (en «sucesión natural») Espacio, tal como confesó a Ricardo Gullón en marzo de ese mismo año:

El poema, cuando se publicó en Méjico, tenía una sola estrofa. Ahora tiene tres, muy amplias. Voy a publicarlas, si las quieren, en Poesía española, revista que me agrada, y las daré en forma de prosa. Para mí, como le dije hace tiempo, sólo es verso lo que tiene asonante o consonante. La rima es la que limita (Gullón 2008: 149).

Por tanto, a pesar de la insistencia de Llansó y otros críticos, no hay por qué creer lo contrario a lo que insinúa el poeta. Además, en unas notas que se conservan en la Sala Zenobia-Juan Ramón, el poeta declaró sus dudas de si publicarlo en México, Argentina o España. Finalmente, él mismo dispuso y remitió la copia del texto en veintiséis folios - mecanografiados y numerados a lápiz en arábigos en el margen superior derecho - a José García Nieto, quien por cortesía entregó a su vez en mano a Gerardo Diego para finalmente ser publicado en abril de 1954, en el número 28 de la revista madrileña Poesía Española dirigida por José García Nieto desde Madrid. El primero de estos folios (que sí era un original mecanografiado) era la portada que contenía el título, subtítulo, la división en tres fragmentos con sus subtítulos correspondientes («Sucesión», «Cantada», «Sucesión»), la datación con el lugar donde se compuso o fue inspirado cada fragmento («Por La Florida, 1941-1942-1954»); y, por último, una dedicatoria ${ }^{23}$ a Gerardo Diego ${ }^{24}$. En estos términos se refería Juan Ramón a la publicación fragmentaria de Espacio en una carta a García Nieto (fechada el 27 de febrero de 1954 en Hato Rey, Puerto Rico) que acompañaba al manuscrito:

Publiqué un tercio de este poema, hace unos diez años, en los Cuadernos americanos, de Méjico, y el resto es inédito. ¿Le interesaría a usted darlo en Poesía española? Creo que se puede meter en seis o siete pájinas, con un tipo de letra intermedio y no escesivamente apretado. Si lo prefiere usted, puede dar sólo lo inédito, es decir, la tercera estrofa, pero es claro que el poema perdería su unidad, los Cuadernos americanos no circulan por España y, además, ha pasado mucho tiempo desde la fecha en que le digo que publiqué una parte del poema (Jiménez 1992: 350).

${ }^{23}$ "A Gerardo Diego, que fue justo al situar, como crítico, el "Fragmento primero" de este "Espacio", cuando se publicó, hace años, en Méjico. Con agradecimiento lírico por la constante honradez de sus reacciones» (Jiménez 2005b: 1267).

${ }^{24}$ Acerca de la admiración por Juan Ramón y el entusiasmo de los comentarios realizados por Gerardo Diego sobre Espacio, léase el articulo de Francisco Javier Díez de Revenga, «Gerardo Diego, Juan Ramón y Espacio», incluido en Cuaderno adrede 4 (pp. 43-49). 


\section{Como declara Almudena del Olmo Iturriarte en «Historia editorial de Es- pacio»:}

José García Nieto no desaprovecha la oportunidad que le brinda quien en esos momentos es el poeta español vivo de mayor prestigio, y sólo dos meses más tarde, en abril de 1954, el extenso poema en prosa, en su versión íntegra tal como sugiere Jiménez, ve la luz por vez primera en el número 28 de Poesía Española (pp. 1-11) (Olmo Iturriarte 2007: 51).

Se publicó finalmente en tres fragmentos y prosificado con la dedicatoria a Gerardo Diego, el primero en ser consciente de la importancia de nuestro poema extenso en el panorama de la poesía universal. Tras tal dedicatoria, el poeta cántabro le remitió una carta al poeta el 7 de junio de 1954 diciéndole:

Estoy como chico con zapatos nuevos con su generosa dedicación de Espacio. Nada podía hacerme más ilusión por lo que significa su gesto de simpatía, por las palabras tan nobles e inmerecidas de la dedicatoria y por la radiante, caudalosa hermosura de su máximo poema. [...] Parece imposible en principio cantar tan sostenido en un poema absolutamente lírico, plenamente poético, sin apoyos argumentales (aunque sí con tanta vida registrada en torno) y cantar sin desmayo con embriagada lucidez. Hazaña de poeta a la que no encuentro fácil parangón (Diamante parangón de la poesía) (Diego 2000: 46).

La cita nos parece significativa, en tanto que trae a colación la conocida polémica de Poe sobre la imposibilidad de que un poema extenso sea «absolutamente lírico» y capaz de sostener el aliento emocional «sin desmayo» a lo largo de cientos de versos o líneas de texto. Espacio, por el contrario, es uno de los poemas largos que cumplen las expectativas de mantener intensión a pesar de la extensión. Es, como decía Valéry, una exclamación continuada. Y es que, al margen de la intencionalidad que Juan Ramón tuviera de elaborar un discurso poético donde refiriera sus vivencias ${ }^{25}$, el propósito del poema es otro, como bien explica a Ricardo Gullón: expresar sus ansias de totalidad a través de la palabra poética. El crítico y escritor de Astorga, en su artículo «Introducción a Espacio» (1981), resumía así las vivencias y la actividad poética de Juan Ramón Jiménez en el periodo de gestación del poema:

Obviamente, Juan Ramón aspiraba a la plenitud y es posible que parte de sus zozobras mentales fueran causadas por ese afán de totalidad que, ciertamente,

${ }^{25}$ La recién publicada Vida y obra poética de Juan Ramón - a partir de las carpetas que la familia de Juan Ramón conservaba bajo el rótulo de VIDA - forma parte de un intento más de «Obra total» y de reordenación de su escritura en prosa y en verso. Vida. Vol. 1. Días de mi vida (2014) ha sido editado a cargo de M. Julià y M. Á. Sanz Manzano como una «autobiografía sencilla», a partir de los «esquemas autobiográficos», «notas» y «aforismos» que el poeta de Moguer seleccionó y fueron hallados entre sus papeles con la indicación explícita de que figuraran en Vida. 
logró en poemas como Espacio. No es sólo que pretendiera resumir la multiplicidad de sus vivencias, sino que pretendía concentrar en un objeto poético y potenciar hasta el último grado la energía creativa que poseía y que desde muy pronto le incitará a la perfección (Gullón 1981: 3).

\section{MANUSCRITOS, HISTORIA EDITORIAL, RECEPCIÓN Y APARATO CRÍTICO DEL POEMA}

Uno de los aspectos más controvertidos en el estudio de Espacio es saber cuál de los dos manuscritos originales que se conservan es la versión definitiva: el primero $^{26}$ es el de la Sala Zenobia y Juan Ramón Jiménez de la Universidad de Puerto Rico, en el Recinto de Río de Piedras, donde existe también una especie de «Borrador jeneral», como lo llama el poeta, en el que aparece el texto en verso seguido y sin cortes. En la edición de Llansó, además de este manuscrito, se reproducen en facsímil (Apéndice 4. 1-6) los distintos borradores iniciales que muestran la génesis originaria del poema; el segundo manuscrito (que no reproduce la edición de Llansó y Bejarano) es el de la Fundación Gerardo Diego ${ }^{27}$ — no publicado hasta 2007 en facsímil- y fue base de la edición de 1954 para la revista Poesía Española. Juan Ramón envió esta copia manuscrita a José García Nieto que, a su vez, se la entregó a Gerardo Diego y éste guardó en su archivo personal hasta ser descubierta en el seno de su fundación en 2007. Esta última, al parecer, es la copia definitiva ${ }^{28}$ por ser la última corregida, mecanografiada a mano y revisada por el poeta («clarísima y sin riesgo de erratas», decía José García Nieto en su solicitud); no obstante, con-

${ }^{26}$ Este manuscrito fue objeto de una reproducción facsimilar editada por Ricardo Gullón en la revista santanderina Peña Labra. Pliegos de Poesía (Santander), núms. 40-41, Verano-Otoño, 1981; y, más recientemente, por la Fundación Juan Ramón Jiménez, al cuidado de Luis Manuel de Prada.

${ }_{27}$ Para nuestro estudio, hemos consultado este segundo manuscrito en: Cuaderno Adrede, $\mathrm{n}^{\mathrm{o}}$ 4, Santander, Publicaciones de la Fundación Gerardo Diego, abril 2007.

${ }^{28}$ Se trata de una copia mecanografiada sobre folios de papel carbón en su mayor parte, con alguno original (como la portadilla) donde se aprecian algunas correcciones manuscritas a lápiz o hechas a tinta. Por ser la última copia corregida de su puño y letra, y por la expresa voluntad del poeta de que fuera dada a la luz en la mencionada revista, consideramos que esta versión — desconocida hasta la edición facsímil de 2007- es la definitiva y debería ser tomada como punto de referencia ecdótica teniendo en cuenta la resolución anotada a lápiz de las dobles opciones que presentaba la primera versión de Puerto Rico y las correcciones hechas por el propio autor (casi las mismas que la de la copia de la Sala Zenobia-Juan Ramón), que fijan definitivamente el texto. No obstante, como avanzaba Olmo Iturriarte en su edición para Espasa, en los apéndices o en las notas adicionales de esa posible futura edición, no se deberían obviar - como variantes textuales posibles - «las modificaciones que el texto presenta eventualmente en la Tercera antolojía poética, en Leyenda, en El otro costado y en Lírica de una Atlántida» (Olmo Iturriarte 2005: 1264). 
tenía mínimas erratas y no comprendía el prólogo de 1943, que sí estaba en la copia de Puerto Rico.

En vida del autor, Espacio se volvió a publicar a cargo de Eugenio Florit y la propia Zenobia en 1957 en la Tercera antolojía poética (1898-1953), ocupando la parte central del «Libro 36» (En el otro costado); pero, como todas las ediciones anteriores a 2007, esta versión no reproducía íntegramente algunas líneas - como los ejemplos concretos de las distintas formas que adoptaba el «Destino» en nuestras vida- omitidas del tercer fragmento, que estaban en la copia enviada a García Nieto y en la de Puerto Rico. Las reproducimos aquí:

Esbirro militar de Unamuno. Caricatura infame (Heraldo de Madrid) de Federico García Lorca; Pieles del Duque de T'Serclaes y Tilly (el bonachero sevillano) que León Felipe usó después en la Embajada mejicana, bien seguro; Gobierno de Negrín, que abandonara al retenido Antonio Machado enfermo ya, con su madre octojenaria y dos duros en el bolsillo, por el helor del Pirineo, mientras él con su corte huía tras el oro guardado en la Banlieu, en Rusia, en México, en la nada... (Jiménez 2012: 145).

De estas líneas, sólo la primera frase «Esbirro militar de Unamuno» ${ }^{29}$ fue tachada a carbón por Juan Ramón sobre el folio 17 de la copia enviada a Madrid. Eran unas líneas que, aunque con referencias explícitas en el poema Tiempo, no se incluyeron en Espacio por recomendación de Zenobia. Trataban, como hemos visto, sobre hechos ocurridos en la guerra civil y en ellos había ciertos calificativos hacia escritores vivos que podían resultarles ofensivos. Este asunto fue motivo de escándalo en el mundillo literario en 2007 porque Alegre en su artículo dejaba entrever una intención política en el hecho de que editores posteriores a la publicación del poema en la Tercera antolojía poética (1898-1953) hubieran decidido aceptar como buena la mutilación hecha sin dar ninguna explicación, silenciando el problema de fondo y censurando ésta y otras líneas que se hallaban en la edición de la Universidad de Puerto Rico. Desde nuestro punto de vista, Alegre tiene razón y tal vez algunos editores posteriores de Juan Ramón (como Aurora de Albornoz) se encontraron más o menos satisfechos con la mutilación del texto original de Espacio y, por eso, la mantuvieron. La tesis que deja clara Alegre es que, en definitiva, la Tercera Antolojía - llevada a cargo por Eugenio Florit y la propia Zenobia- fue víctima de la censura política franquista a través de un largo proceso de amputación que Juan Ramón y su esposa aceptaron con resignación. Retomando la cuestión de las ediciones del poema, Alfonso Alegre supone que, después del envío a la revista española, la copia de Puerto Rico fue revisada por Juan Ramón realizando correcciones mínimas, en ocasiones ultracorrecciones erróneas. La edición de Llansó coteja ambas copias y permite comprobar que la de

29 Dicha frase se refiere al enfrentamiento que tuvo lugar entre Unamuno y el general Millán-Astray en el paraninfo de la Universidad de Salamanca el 12 de octubre de 1936. 
Puerto Rico procede de la original de Poesía Española, y aprecia algunas rectificaciones posteriores a la copia enviada a García Nieto hechas a carbón y otras mecanografiadas, que bien podrían ser errores involuntarios. Cabe alegar además que la copia de la Sala Zenobia-Juan Ramón Jiménez de Puerto Rico contiene anotaciones de las que se infiere su carácter provisional. Un ejemplo claro de ello es un primer folio previo al manuscrito, que comprende la siguiente observación: «Espacio. 3 Fragmentos: (Sucesión). Darlo completo en Méjico. Después de publicarlo en ¿España? ¿o en Arjentina?» (Jiménez 2012: 419). Esto querría decir que la copia de Puerto Rico es previa o coincide con un momento en que el poeta no tiene la seguridad de dónde publicaría la versión definitiva de Espacio. Por lo que respecta al prólogo, que sí incluye la copia portorriqueña, se trata de un folio aparte que reproduce el borrador del que contenía la versión publicada en 1943 de Espacio (una estrofa) en Cuadernos Americanos, ya que a pie de página añade la datación de la primera versión: «Por La Florida 1941-...». Se podría pensar que el contenido de este prólogo (a pesar del interés que tiene para el estudioso del texto) era adecuado para la primera versión del poema, pero ya no lo era para la definitiva en tres fragmentos. A nuestro juicio, aunque por las razones ya expuestas consideramos que la copia de Poesía Española es la definitiva, la mejor lectura y edición debería ser - como la elaborada por Almudena del Olmo Iturriarte para la BLU de Espasa - la que contraste ambos originales.

Reseñemos ahora las ediciones completas de Espacio tras su edición en 1954. Fue recuperado, como hemos dicho, tres años después en Tercera antolojía poética (1898-1953), en cuya edición desaparecían las alusiones personales a cierto personajes conocidos y había mínimas diferencias: algunos casos de puntuación y la posición de los subtítulos («Sucesión-Cantada-Sucesión»). Desde esta edición, el poema estuvo quince años sin publicarse de manera íntegra hasta que 1972, año en que María Teresa Font lo edita como parte de lo que sería hasta el momento el primer estudio riguroso del poema: Espacio: autobiografía lírica de Juan Ramón Jiménez. En 1974, Aurora de Albornoz — siguiendo las indicaciones juanramonianas - colocó Espacio en la tercera parte del libro En el otro costado. También agregó en un apéndice las versiones de los dos primeros fragmentos en verso libre conforme aparecieron en la revista mexicana Cuadernos Americanos en 1943 y 1944. Además, añadió el «Prólogo», eliminado en la edición definitiva, y unas notas incompletas. En 1978, Antonio Sánchez Romeralo edita el poema en Leyenda (1986-1956), primero de los libros de la obra completa que el poeta pensaba publicar bajo el título de Unidad: Obra poética. «Espacio», precedido del «Prólogo», se publicó por primera vez en la versión del original mecanografiada de la Sala Zenobia-Juan Ramón, formando parte de la sección quinta del libro 42 de En el otro costado, estructurado en siete secciones y alterado en el orden con respecto a la copia de la Sala Zenobia-Juan Ramón y la de la Tercera antolojía poética, donde ocupaba la tercera sección. En 1981, la revista Peña Labra de Santander, al 
cuidado de Ricardo Gullón, dio a conocer por primera vez la reproducción facsimilar del original mecanografiado y corregido a mano de la Sala Zenobia-Juan Ramón. En 1982, la misma Aurora de Albornoz ofreció — con apéndices y una interesante aportación crítica- su edición exclusiva de Espacio. En 1986, Arturo del Villar editó conjuntamente Espacio y Tiempo por primera vez en un solo volumen, tal como su autor quiso hacer en una de las muchas ordenaciones de su obra. A Arturo del Villar le debemos también un completo estudio de Tiempo, cuyo original consta de cuarenta y dos hojas de las que las cinco primeras aparecen en versión casi definitiva y las restantes, corregidas para ser copiadas de nuevo, o con numerosos espacios en blanco destinados a ser completados en futuras correcciones. De esto se deduce que, aunque Tiem$p o$ fuera dividido luego en siete fragmentos, surgió de un tirón y fue escrito inicialmente de forma ininterrumpida. Retomando la historia editorial de Espacio, el poema sería de nuevo publicado - junto a un exhaustivo análisis - por Mercedes Julià en 1989, con título El universo de Juan Ramón Jiménez (un estudio del poema Espacio). Le siguen varias ediciones facsimilares (19901996) y la reproducción - tal como aparecía en Leyenda - en diversas antologías: destacamos la mencionada Lírica de una Atlántida, realizada por Alfonso Alegre Heitzmann en 1999; o compilaciones de la obra completa (anteriores a la edición de Llansó y Bejarano de Espacio y Tiempo por separado en 2012), como las aludidas ediciones de Javier Blasco y Teresa Gómez Trueba de la $\mathrm{BLU}$, que por la rigurosa reconstrucción ecdótica que los distintos editores han llevado a cabo deben considerarse en estos momentos como la edición canónica de la obra juanramoniana.

La otra cuestión que pone en jaque a la crítica es si, tras la definitiva versión prosificada de 1954, es pertinente o no que el contexto de publicación de Espacio sea la quinta sección de En el otro costado. Respecto a este aspecto, estamos de acuerdo con la observación que la estudiosa Almudena del Olmo Iturriarte hace al respecto en su «Historia editorial de Espacio»»

Como respuesta tal vez pueda afirmarse que Juan Ramón Jiménez pensó incluir Espacio en el conjunto de En el otro costado, imponiendo a la génesis del texto unos criterios de ordenación de la obra a los que posteriormente, en su evolución, el texto escapa. Se difumina la barrera temporal de 1942, pues la composición del poema se dilata hasta 1954. Se expande sobre el criterio de localización espacial, porque si Espacio empieza a componerlo Jiménez por La Florida lo concluye en Puerto Rico. Y lo que es más importante, el texto acaba desatándose de los criterios formales que, forzando la simetría, motivan su inclusión en la parte central de En el otro costado (Olmo Iturriarte 2009: 158-159).

Tras este extracto histórico de la historia editorial y ecdótica de Espacio, pasamos a considerar la recepción inicial del texto y la hermenéutica generada.

${ }^{30}$ Incluido en Las poéticas sucesivas de Juan Ramón Jiménez. 
El eco de Espacio en su tiempo fue desigual y, en términos generales, decepcionante; en parte, porque Juan Ramón generaba muchas hostilidades (especialmente entre los poetas españoles de su tiempo); y en parte también porque, hasta Espacio, no existía en la literatura española un referente de moderno poema extenso. A ello se añade que el texto fue tachado de pretencioso o no fue entendido. Juan Larrea, exiliado entonces en México y fundador de la revista Cuadernos Americanos, en 1943 y 1944 recibió con entusiasmo los dos primeros fragmentos y los publicó. Como hemos podido comprobar, también Gerardo Diego (recordemos su artículo de 1948 en Alférez, «Nostalgia de Juan Ramón») fue uno de los primeros en darse cuenta de su importancia y en manifestarlo públicamente. Sin embargo, otros poetas del grupo del 27 emitieron juicios críticos negativos sobre el poema largo de Juan Ramón. Pongamos como ejemplo a Luis Cernuda quien, tras la polémica que surgió por arremeter contra el grupo de poetas del 27 en las páginas del número 34 de la revista Orígenes, dio un giro radical en su opinión sobre el poeta. Otro caso palmario fue el de Jorge Guillén, quien en una carta del 7 de octubre de 1943 escribe a Salinas: «¿Has visto el número cinco de Cuadernos Americanos? Otro J.R.J.: más de cuatrocientos versos seguidos, un párrafo fofo reblandecido por esa nota mema que tiene siempre el pensamiento del tal nenúfar» ${ }^{31}$. En cuanto a la recepción de Espacio entre los poetas jóvenes de los años cincuenta, habría que decir que la mayoría de éstos estaban defendiendo entonces una poesía con trasfondo social y de carácter realista. Esto supuso que el poema de Juan Ramón no fuera visto con buenos ojos $\mathrm{y}$, en definitiva, que la obra última de Jiménez no llegase a España, o fuese excluida de las principales antologías de la época por la «pérdida de vigencia histórica». Ángel González y Jaime Gil de Biedma son ejemplo de dos de los poetas de la generación del cincuenta que no entendieron muy bien la poesía última del poeta onubense. Así, el primero, aunque le dedicara una antología publicada en 1974 en la Colección Los Poetas de la editorial Júcar e influyera tanto en su obra posterior, se refirió a la poesía final de Juan Ramón como «el jeroglífico en que desemboca su extensa obra lírica». El segundo calificó a Juan Ramón de «poeta menor» y lo insultó abiertamente. Hubo excepciones, como son los casos de Francisco Brines, Ángel Crespo, José Hierro o Tomás Segovia quien, exiliado desde el final de la guerra, publicó en México en 1954 un magnífico artículo sobre la poesía última de Juan Ramón con el título de «Actualidad de Juan Ramón». No obstante, el reconocimiento de Espacio y de su poesía última vinieron fundamentalmente de fuera de España, con Lezama Lima y los poetas cubanos del grupo «Orígenes»; y, especialmente, de Octavio Paz, que consideraba el poema extenso de Jiménez como uno de los textos capitales de la poesía moderna. Así lo corroboran las palabras

31 Transcribimos el fragmento de dicha carta citado indirectamente del número especial dedicado a Juan Ramón en el suplemento «Culturas», La Vanguardia, Miércoles, 15 septiembre de 2004, p. 3. 
escritas en 1956 con motivo de la entrega del Premio Nobel: «Espacio es uno de los monumentos de la conciencia poética moderna y con ese texto capital culmina la interrogación que el gran cisne hizo a Darío en su juventud» (Paz, 1986: 95). Esta admiración se aprecia también en la composición de su nombrado poema extenso Pasado en claro, claramente juanramoniano; pero, curiosamente, la influencia no procedía del Espacio en prosa, sino en verso. Esto nos lleva a otro de los aspectos polémicos del poema: la controversia de la crítica de la época en torno a la conveniencia de haber prosificado el poema y sobre cuál de las dos ediciones es la pertinente. Añadamos que no hay especialista de Juan Ramón que no haya cuestionado positiva o negativamente el hecho de que al final de su vida decidiera prosificar su poesía. Realmente, la polémica surgió de la mano del mismo Octavio Paz en su artículo «Una de cal...» ${ }^{32}$, donde declaraba: «Se pierde así la percepción visual del ritmo. La masa compacta de la prosa impide ver la respiración de la escritura, la forma de su voz y la de su silencio» (Paz 1999: 1045). Por el contrario, Aurora de Albornoz en el estudio de su edición de 1982 opina que la prosificación responde a la exigencia de la propia naturaleza del texto, que busca expresar la inmensidad de las marismas y del arrecife de coral a través de aquel eterno párrafo no quebrado en un confinante fin de verso. Tomás Segovia — en unas declaraciones de 2004 a La Vanguardia publicadas en el suplemento «Culturas» el 15 de septiembre - coincide con Paz en su incomprensión hacia ese gesto juanramoniano de prosificar su texto sin modificar el originario escrito en verso libre: "Yo leí Espacio en plena juventud, primero en el anticipo, en verso, publicado en Cuadernos Americanos en México, y debo decir que nunca entendí por qué J.R.J. lo publicó después en una supuesta prosificación en la que no cambia nada» (Sánchez Robayna 2004: 6). Nicanor Vélez ${ }^{33}$ justifica —como Albornoz- la prosificación a través de la horizontalidad de la realidad que representa, alegando incluso que no hay cambio de ritmo del verso libre a la prosa poética:

Es evidente que desprovisto de rima - «la rima es un invento tardío del ritmo», decía Juan de Mairena-, al poema en prosa lo articula, fundamentalmente, el ritmo. Pero, téngase en cuenta que al pasar del poema en verso mayor a prosa, el cambio del ritmo nunca es radical, lo esencial se mantiene, aunque las pausas se sumerjan y cambie la sensación del movimiento; de caída en cascada para a una especie de movimiento en ola. El poema se hace mar. Espacio en movimiento: tiempo (Vélez 2006: 218).

Desde nuestro punto de vista, la primera versión en verso libre gana con respecto a la prosificada, que - por mucho que la idea del poema sea expresar

\footnotetext{
32 Publicado en 1967 en el número CXL de Papeles de Son Armadans.

33 En su mencionado artículo: «Espacio o el movimiento del tercer mar de Juan Ramón Jiménez».
} 
la omnipresencia de una realidad discursiva abierta, inmensa y lineal- consideramos poco natural e incompleta, en el sentido de que cada verso pierde la posibilidad de destacarse y ocupar el espacio y la atención visual que su sentido exige. De hecho, el mismo autor en la charla «Poesía cerrada y poesía abierta» ${ }^{34}$ recordaba que la poesía tiene que ver más con la música que con la pintura y lo visual; quizás por eso Jiménez recurría siempre al ejemplo del ciego: «Para un ciego el verso y la prosa serían iguales. Y en realidad no existe el verso más que por el consonante o el asonante, por la rima. El ciego es siempre una gran autoridad para la escritura poética» (Jiménez 1970: 195). Estas palabras de Jiménez rebaten los argumentos de Albornoz y Vélez al demostrar que, aunque existe la intención de reflejar la inmensidad del referente espacial de Miami a través de la disposición textual, no es lo esencial. Como afirmaba Valéry, la prosa es marcha o desfile; y la poesía, danza y ritmo que ya lleva implícito el principio analógico y la correspondencia entre realidad e imagen (no hablamos de «metro»: dos endecasílabos de dos poetas tienen la misma medida, pero no el mismo ritmo). Nuestro poema es esencialmente musical, sinfónico y circular, como el respirar o como una sinfonía que se cierra sobre sí misma para volver a repetirse desde un motivo recurrente o tema. Al respecto, Almudena del Olmo Iturriarte considera la audacia de Juan Ramón en su largo proceso de composición al poner en jaque los límites difuminados entre verso libre, prosa métrica y prosa lírica. La estudiosa aclara que la forma métrica de los dos primeros fragmentos de la edición mexicana, Espacio (Una estrofa), constituyen una sola estrofa en verso suelto, sin rima y con forma de «silva libre» (variante sin rima alguna de la silva modernista). De esta manera la especialista explica la arquitectura textual de lo que el poeta en 1944 publicará como «Fragmento primero» y «Fragmento segundo» para la misma revista Cuadernos americanos: «evidencia un predominio absoluto del metro impar, preferentemente, endecasílabos, heptasílabos, eneasílabos y pentasílabos - lo que Juan Ramón denomina verso blanco - o combinaciones asimétricas varias de estos metros - lo que Jiménez considera verso libre-》 (Olmo Iturriarte 2009: 159). A este cambio de la forma visual del texto lo llama el poeta «prosa seguida», porque está constituida por líneas que parecen prosa poética, pero se trata más bien de una prosa métrica que surge de la mera sucesión y adición de los versos iniciales manteniendo el ritmo y el metro originales. Sin embargo, con el «Fragmento tercero», publicado por primera vez en Poesía española, cambia el aspecto visual de la composición. Diríamos que ya no es verso libre ni prosa métrica, sino prosa poética o lírica con algunos momentos aislados de prosa métrica. Esto último sucede sobre todo cuando Juan Ramón engarza en su texto poemas publicados anteriormente en revistas como «Leyenda de un héroe hueco», y otros ya mencionados.

${ }^{34}$ La edición consultada es la citada: Pájinas escogidas. Prosa (1970), pp. 179-210. 
Prosiguiendo nuestro recorrido histórico por el ámbito de la recepción del poema Espacio, afirmemos que, aunque los estudios a fondo del poema se hicieron esperar bastante, fue Enrique Díez-Canedo el primer crítico que en 1944 señaló la aparición del fragmento primero de Espacio como el posible inicio de una nueva época juanramoniana. No obstante, el primer apunte crítico del poema íntegro surgió el 26 de agosto de 1954, en un artículo publicado por Gerardo Diego en El Noticiero Universal donde declaraba: «Este cauteloso, este acendrado poema es tan avaro, tan ceñido, tan conciso como pueden serlo los momentáneos poemas de Estío o Piedra y cielo». Guillermo de Torre ${ }^{35}$ se refirió al poema en 1957, dando ciertas claves para su interpretación: «Superando lo fragmentario, alcanza lo orgánico, con vuelo largo e ímpetu seguro. En cierto modo, por su espíritu y contenido, "Espacio" puede ser considerado también una summa y balance de toda su vida y obra poéticas» (Torre 1957: 60); o «Aparece en ella una suerte de sentimiento cósmico, una objetivación de lo íntimo, que antes no se había dado en el poeta» (ibíd.: 5960). En el mismo año, Eugenio Florit ${ }^{36}$ escribía: «Este extenso poema repleto de recuerdos de vida pasada y presente, está todo él pensado en tono mayor y lo tengo por un gran grito de afirmación, como una nueva oda de estar, de ser en el mundo y dentro del amor» (Florit 1957: 308). También en 1957, Oreste Macrín ${ }^{37}$ opinaba que todo universo juanramoniano «emana, como en la cosmogonía de Plotino, desde lo eterno en sí mismo, identificándose con su conciencia poética, y la conciencia con él» (Macrí 1957: 290). En 1957, Graciela Palau de Nemes ${ }^{38}$ consideraba importante la fuerza ambiental que inspiró el poema y las circunstancias psíquicas que lo propiciaron: «El paisaje floridano ejerció una tremenda influencia en el espíritu del poeta. La Florida es un arrecife completamente plano y, como todas las grandes extensiones, comunica al hombre un sentimiento de inmensidad y de eternidad». Comparó además el poema de Juan Ramón con algunos de Eliot, pero confesaba que mientras en «Eliot el poema de sucesión da la impresión de ser producto de creación artística, en Juan Ramón parece inspiración espontánea» (Palau de Nemes, 1974: 316). En 1961, Antonio Sánchez Romeralo ${ }^{39}$, estudiando Animal de fondo, dedicaba algunos párrafos a Espacio: «Estación total y Espacio son dos libros escritos bajo el signo de lo eterno y lo inmanente al mismo tiempo» (Sánchez Romeralo 1961: 304). Y, con respecto al fragmento tercero, nos dice: «Juan Ramón no quiere, como en el misticismo hindú, diluirse en el mundo despersonalizándose, sino potenciar su personalidad incorporándose al mundo, diluido en su espíritu» (ibíd.: 304). Como apuntábamos en el apartado anterior,

\footnotetext{
35 En su artículo «Cuatro etapas de Juan Ramón Jiménez».

36 En «La poesía de Juan Ramón Jiménez».

37 En «El segundo tiempo de la poesía de Jiménez».

38 En Vida y obra de Juan Ramón Jiménez (1957).

39 En su artículo, «Juan Ramón Jiménez en su fondo de aire».
} 
Antonio Sánchez Barbudo ${ }^{40}$ en 1962 planteó por primera vez la cuestión de la fecha de composición del tercer fragmento. En 1965, en la edición francesa de El arco y la lira, Paz agregaba el capítulo "Verso y prosa», un valioso análisis de algunos grandes poemas universales entre los que sitúa Espacio (al que llama «Strophe»), que como decíamos para el mexicano es el mejor poema de Juan Ramón Jiménez y uno de los textos poéticos mayores del siglo $\mathrm{XX}$. Otros estudios con cierto interés, que por aquellos años mencionaban el poema de Juan Ramón, fueron: La obra en prosa de Juan Ramón Jiménez (1966), en primer término, donde el crítico M. P. Predmore justificaba el cambio de Espacio de verso libre a prosa como consecuencia del deseo del autor por liberar la poesía del corsé de la rima; o en segundo lugar, El poeta y la poesía (1966) de Biruté Ciplijauskaité, que sitúa Espacio en la segunda época de Jiménez.

Sin embargo, los estudios extensos en torno al poema se hicieron esperar hasta 1968, año en que se publica el revelador ensayo de Howard T. Young ${ }^{41}$. Años más tarde, en 1972, se editaría el primer estudio exhaustivo del poema, Espacio, autobiografía lírica de Juan Ramón Jiménez de María Teresa Font, que por fin dignifica el texto comparándolo con poemas extensos como Una tirada de dados, La tierra baldía o Muerte sin fin. Para Font estos poemas trascienden el propósito del arte y son la «expresión de una metafísica que aspira a penetrar los misterios esenciales de hombre-Dios-cosmos» (Font 1972: 213). Le siguen las cuarenta páginas dedicadas a Espacio en la tesis doctoral de Gilbert Azam en 1980 sobre la poesía de Juan Ramón; el artículo de Gullón, «Un ascua de conciencia y de valor», donde comenta el texto como una conciencia que se va creando a medida que se crea el poema; «De Espacio a Piedra de Sol» de Arturo del Villar, que compara ambos poemas por sus estructuras circulares; o el artículo «Una improvisación del cosmos: Espacio, de Juan Ramón Jiménez», de Agnés M. Gullón, donde se realiza una interesante aproximación a algunos puntos clave del poema que habían pasado desapercibidos. En 1981, Mervyn Coke-Enguídanos escribe «Juan Ramón Jiménez explora el espacio», donde estudia el poema dentro de su marco espacio-temporal, relacionándolo con $L a$ Biblia a través de sus alusiones a ella: «Puede leerse como la respuesta de Juan Ramón a interrogantes similares a las que Dios presentó a Job» (Coke-Enguídanos 1981: 199). Por fin, en 1989, se publicaría uno de los hitos en la crítica del poema: El universo de Juan Ramón Jiménez (Un estudio del poema «Espacio») de Mercedes Julià. A nuestro juicio, se trata del estudio más exhaustivo divulgado hasta ahora sobre Espacio; sobre todo en el sentido de que se aprecia cómo la autora afronta valientemente su interpretación del texto dejando al margen los aspectos externos al mismo. Más tarde, en el año 1991, con motivo

\footnotetext{
${ }^{40}$ En su estudio, La segunda época de Juan Ramón Jiménez.

${ }^{41}$ El mencionado en el apartado anterior: «Génesis y forma de Espacio, de Juan Ramón Jiménez».
} 
de la celebración del IV Congreso de Literatura Contemporánea de la Universidad de Málaga, la revista Anthropos publicó sus actas en un número monográfico que representaría una puesta al día y una revisión del estado de la cuestión acerca de los estudios juanramonianos. Esto conllevó también la emergencia de nuevas voces críticas que esbozaban originales ideas sobre Espacio. Destaquemos el discurso crítico de Francisco José Díaz de Castro, quien en «Espacio como culminación de la poética de Juan Ramón Jiménez» trató por primera vez la oralidad del poema y las posibilidades expresivas que él apreciaba en el registro dialógico establecido entre el sujeto poético con sus otros yos, y con los símbolos representados en la naturaleza a través del pensamiento analógico. Las líneas que suscribimos del poema de Jiménez evidencian esa oralidad y pulsión dialógica: «Dentro de mí hay uno que está hablando, hablando, hablando ahora. [...] Yo quiero estar tranquilo con la tarde, esta tarde de loca creación (no se deja callar, no lo dejo callar). ¿Calla, segundo yo, que hablas como yo; calla, maldito!» (Jiménez 2012: 149). Otro homenaje, el número 77-78 de marzo-mayo de 2006 en la revista Turia, con motivo del cincuentenario de su muerte, nos brindó la publicación de varios artículos entre los que destacamos el citado de Nicanor Vélez y el celebrado «Espacio y la tradición del poema extenso», de Andrés Sánchez Robayna, donde el autor canario analizaba la naturaleza del poema extenso contemporáneo retomando las aportaciones de Paz — el poeta mexicano definió Espacio como «fragmentos hechos de fragmentos $\rangle^{42}$ - y Eliot, como válidas para determinar la naturaleza del nuevo género poético. Por último, a todas estas monografías referidas, añadamos la importante aportación hermenéutica de Almudena del Olmo Iturriarte con tres análisis del poema: En torno a «Espacio» de Juan Ramón Jiménez ${ }^{43}$ (1995); el estudio introductorio a su edición en Obra poética (2005), para Espasa-Calpe; y los apartados dedicados a Espacio, en Poéticas sucesivas de Juan Ramón Jiménez (2009). O los recientes estudios monográficos de Manuel Martínez Forega $^{44}$ y Ernesto Estrella Cózar ${ }^{45}$, quien adscribe el texto de Jiménez a la tradición del poema en prosa contemporáneo.

A pesar de la emergencia reciente de estudios y el interés que para la crítica actual está suscitando un poema siempre abierto a nuevos asedios críticos, es inevitable que surja la lógica e inquietante pregunta de por qué, después de más sesenta años, existe todavía poca hermenéutica sobre, según palabras de Paz, tal «monumento de la conciencia poética contemporánea». Mercedes Julià señalaba en la introducción a su libro que — además de por lo insólito e incom-

\footnotetext{
42 Entendamos que Espacio es, en parte, un poema compuesto a partir de fragmentos salvados de poemas publicados o inéditos.

${ }^{43}$ Almudena del Olmo Iturriarte (1995). En torno a Espacio, de Juan Ramón Jiménez. Palma de Mallorca: Ensayos Monograma.

${ }^{44}$ Memoria y recuerdo en el poema Espacio de Juan Ramón Jiménez (2009).

${ }^{45}$ Espacio, poema en prosa de Juan Ramón Jiménez (2013).
} 
prensible del texto para la mayoría de lectores y críticos - se debe, sobre todo, a la propia estructura del poema, desalentadora para el analista. Al respecto, el mismo Vélez también refería en su artículo que, ante las interrogantes que plantea el texto no habría que esperar respuesta; tan sólo hay que leer y releer el poema sin esperar hallar nunca un referente claro a sus misterios: «Hará falta leerlo muchas veces, para oír una y mil veces sus múltiples preguntas, que en medio del cosmos apuntan en todas direcciones..., pero sin esperar encontrar una respuesta» (Vélez 2006: 223). Sabiendo de antemano que no hay tal respuesta y, si la hubiera, dinamitaría ese paisaje sembrado de interrogantes que es Espacio, nuestro trabajo pretende ser una pieza más en el constructo discursivo de las lecturas del poema y, de resultas, una reformulación de sus preguntas.

\section{BIBLIOGRAFÍA CITADA}

Alegre, Alfonso (2007). «Génesis, contexto y versión final de "Espacio": algunas consideraciones», Cuaderno Adrede 4. Santander: Fundación Gerardo Diego, pp. 5-41.

Blasco Pascual, Francisco Javier (1987). «Introducción», en Juan Ramón Jiménez. Antología poética. Madrid: Cátedra, pp. 11-104.

Camprubí, Zenobia (1996). Diario 2. Estados Unidos (1939-1950), ed. y trad. G. Palau de Nemes. Madrid: Alianza.

Coke-Enguídanos, Merving (1981). «Juan Ramón Jiménez explora el espacio», La Torre. 29 (111-112 y 113-114), pp. 195-222.

Díaz de Castro, Francisco Javier (1991). «Espacio como culminación de la poética de Juan Ramón Jiménez», en JRJ, poesía total y obra en marcha, Actas del IV Congreso de Literatura Contemporánea de la Universidad de Málaga. Barcelona: Anthropos, pp. 265-287.

Dickie, Margaret (1986). On the Modernist Long Poem. Iowa City: University of Iowa Press.

Diego, Gerardo (2000). Gerardo Diego. Prosa, Tomo VIII, «Prosa literaria» (Volumen 3), ed, J. L. Bernal Salgado. Madrid: Alfaguara.

Florit, Eugenio (1957). «La poesía de Juan Ramón Jiménez», La Torre. 5 (19-20), p. 308.

Font, María Teresa (1972). Espacio: autobiografía lírica de Juan Ramón Jiménez. Madrid: Ínsula.

Gullón, Ricardo (1981). Introducción a «Espacio», Peña Labra. 40-41, p. 3.

Gullón, Ricardo (2008) [1958]. Conversaciones con Juan Ramón Jiménez. Sevilla: Sibila/ Fundación BBVA.

Jiménez, Juan Ramón (1970) [1958]. Pájinas escogidas (Prosa), sel. R. Gullón. Madrid: Gredos.

Jiménez, Juan Ramón (1992). Cartas (Antología), ed. F. Garfias. Madrid: Espasa Calpe.

Jiménez, Juan Ramón (2005a). Obra poética. Vol. 1. Obra en verso, ed. Javier Blasco y Teresa Gómez Trueba. Madrid: Espasa Calpe.

Jiménez, Juan Ramón (2005b). Obra poética. Vol. 2. Obra en prosa, ed. Javier Blasco y Teresa Gómez Trueba. Madrid: Espasa Calpe.

Jiménez, Juan Ramón (2012). Espacio y Tiempo, ed. J. Llansó Martín y R. Bejarano Álvarez. Ourense: Linteo Poesía.

Julià, Mercedes (2001). «Ámbitos americanos en el simbolismo del último Juan Ramón Jiménez», Hispanic Review. 68 (1), pp. 53-71. 
Macrí, Oreste (1957). «El segundo tiempo de la poesía de Jiménez», La Torre. V, 19-20, pp. 289-290.

Olmo Iturriarte, Almudena del (2005). «Introducción a Espacio», en Juan Ramón Jiménez, Obra poética. Vol. 2. Obra en prosa, ed. Javier Blasco y Teresa Gómez Trueba. Madrid: Espasa Calpe. pp. 1247-1264 (vol. 4).

Olmo Iturriarte, Almudena del (2007). «Historia editorial de Espacio», Cuaderno Adrede 4. Santander: Fundación Gerardo Diego, pp. 51-68.

Olmo Iturriarte, Almudena del (2009). Poéticas sucesivas de Juan Ramón Jiménez. Sevilla: Renacimiento.

Palau de Nemes, Graciela (1974) [1957]. Vida y obra de Juan Ramón Jiménez. Madrid: Gredos.

Paz, Octavio (1986) [1956]. «Verso y prosa», en El arco y la lira. México D. F.: Fondo de Cultura Económica, pp. 68-97.

Paz, Octavio (1999b). «Una de cal...» (1967), en Obras Completas, vol. II. Barcelona: Galaxia Gutenberg/Círculo de Lectores, pp. 1032-1051.

Sánchez Barbudo, Antonio (1962). La segunda época de Juan Ramón Jiménez (1916-1953). Madrid: Gredos.

Sánchez Robayna, Andrés (2004). «Espacio y el moderno poema extenso. Poesía sobre la poesía misma», suplemento Culturas de La Vanguardia. Miércoles 15 de septiembre, pp. 4-7.

Sánchez Romeralo, Antonio (1961). «Juan Ramón Jiménez en su fondo de aire», Revista Hispánica Moderna. XXVII, 3-4, pp. 304-305.

Torre, Guillermo (1957). «Cuatro etapas de Juan Ramón Jiménez», La Torre. V, 19-20, pp. 59-60.

Vélez, Nicanor (2006). «Espacio o el movimiento del tercer mar de Juan Ramón Jiménez», Turia. 77-78, pp. 212-224.

Fecha de recepción: 8 de julio de 2016.

Fecha de aceptación: 25 de noviembre de 2016. 